Apuntes del CENES

ISSN 0120-3053

Volumen $35, \mathrm{~N}^{\circ} 61$

Artículo de investigación

Enero - Junio 2016

Págs. 267-302

\title{
Diferencias salariales por género en el departamento de Santander, Colombia
}

\author{
Gender wage gap in departament \\ of Santander, Colombia
}

\author{
Diferenças salariais por gênero \\ em departamento de \\ Santander, Colombia
}

Alexandra Cortés Aguilar**

María Alejandra Flórez Vera ${ }^{* * *}$

Fecha de recepción: 1 de septiembre de 2015

Concepto de evaluación: 9 de noviembre de 2015

Fecha de aprobación: 9 de diciembre de 2015

Este artículo es resultado del proyecto de investigación "Determinantes de los ingresos salariales en Santander ¿existe discriminación salarial por género", con código 1378, financiado por la Vicerrectoría de Investigación y Extensión, UIS.

** Profesora de la Escuela de Economía y Administración, Facultad de Ciencias Humanas, Universidad Industrial de Santander. PhD. Universidad de Granada, España. Líder del Grupo Estudios en Microeconomía Aplicada y Regulación, EMAR. Dirección postal: carrera 27 - calle 9 Ciudad Universitaria, Facultad de Ciencias Humanas (Bucaramanga, Colombia). Correo electrónico: alexacor@uis.edu.co.

*** Investigadora del Grupo Estudios en Microeconomía Aplicada y Regulación EMAR. Economista de la Universidad Industrial de Santander. Dirección de correspondencia: carrera 27 - calle 9 Ciudad Universitaria. (Bucaramanga, Colombia). Correo electrónico: maria.florez4@correo.uis.edu.co 


\section{Resumen}

Este trabajo analiza los factores que influyen en el salario por hora y sus diferencias por género para el departamento de Santander durante los años 2012 a 2014. Específicamente, se explora si dicho diferencial obedece o no a un factor discriminatorio en el mercado de trabajo santandereano, utilizando los datos proporcionados por la Gran Encuesta Integrada de Hogares GEIH. Luego de presentar un análisis descriptivo del mercado laboral santandereano, se realizan estimaciones econométricas aplicando la metodología Blinder-Oaxaca para evidenciar la existencia de un componente discriminatorio. Los resultados indican que, para el total de la muestra en la región santandereana, entre un $25 \%$ y $30 \%$ de las diferencias salariales por género se asocian al componente discriminatorio no explicado.

Palabras clave: capital humano, género, determinantes salariales, diferencias salariales, discriminación salarial.

Clasificación JEL: C32, J15, J16, J31, J71.

\section{Abstract}

This paper analyzes the factors that influence hourly wage and their differences by gender, for the Department of Santander, Colombia, during the years 2012 to 2014. Specifically, it explores whether the differential is due or not to a discriminatory factor in labor market of Santander, using data from Colombian household survey "Gran Encuesta Integrada de Hogares GEIH". After the descriptive analysis of the labor market in Santander, we make econometric estimations using the Blinder Oaxaca methodology to prove the existence of a discriminatory component. Results indicate that, for the total sample in the Santander region, between $25 \%$ and $30 \%$ of the wage differentials by gender are associated to the unexplained discriminatory component.

Keywords: human capital, gender, wage determinants, wage differentials, wage discrimination. 


\section{Resumo}

Este artigo analisa os fatores que influenciam o salário por hora e suas diferenças por gênero para o departamento de Santander durante os anos de 2012 a 2014. Especificamente, explora-se se o diferencial obedece ou não a um fator discriminatório no mercado de trabalho de Santander, utilizando os dados fornecidos pela Gran Encuesta Integrada de Hogares, GEIH. Após apresentar uma análise descritiva do mercado de trabalho de Santander, realizam-se estimações econométricas aplicando a metodologia de Blinder-Oaxaca para evidenciar a existência de um componente discriminatório. Os resultados indicam que, para a amostra total na região de Santander, entre $25 \%$ e $30 \%$ das diferenças salariais por gênero estão associadas ao componente discriminatório não explicado.

Palavras-chave: capital humano, gênero, determinantes salariais, diferenças salariais, discriminação salarial. 


\section{INTRODUCCIÓN}

Tras la Segunda Guerra Mundial se presentaron significativas trasformaciones económicas, sociales, culturales, demográficas, entre otras, que dieron paso a cambios en el tamaño, estructura y rol funcional de los hogares (García, 1989). A partir de 1945 la participación femenina en el mercado laboral aumentó de forma notable. Según Sivard (1985), entre 1950 y 1985 el número de trabajadoras, tanto en países industrializados como en desarrollo, llegó incluso a duplicarse. Los mayores niveles educativos, procesos de urbanización y tercerización del empleo, predominantes en el siglo $\mathrm{XX}$, permitieron que la participación laboral femenina fuera de la mano con el crecimiento del sector servicios, concentrando a las mujeres en determinadas ocupaciones que por lo general contaban con menor estatus y remuneración que aquellas en las que se encontraba localizada la población masculina (García, 1989; Flórez, 2004; Alcañiz, 2012; Guzmán \& Torado, 2001).
Estas discrepancias en el mercado laboral, en relación con la ocupación y remuneración por género, motivaron el interés de investigadores sociales, y su relevancia ha ido en ascenso a medida que la participación femenina en el mercado de trabajo también aumenta (Brizuela \& Tumini, 2008, Fernández, 2006). La evidencia empírica ha demostrado que, aunque las variables de capital humano determinan el nivel salarial, es fundamental tener en cuenta la existencia de otros factores no observables que pueden influir en la determinación de los salarios: la rama de actividad, la ocupación o los problemas de discriminación salarial por grupos, entre otros.

En Colombia, la participación laboral de las mujeres se ha duplicado en las tres últimas décadas, principalmente por la mayor vinculación de las mujeres casadas o en unión libre, y de las mujeres con bajo nivel educativo (Peña et al., 2013). Sin embargo, esta incursión femenina en el mercado de trabajo se ha visto acompañada de una significativa desigualdad en los 
ingresos laborales frente a la remuneración percibida por los pares masculinos. Entretanto, a nivel regional, en el departamento de Santander se han implementado estudios, apoyados por la Gobernación, sobre las brechas de género en varias dimensiones, a saber: educación, ingresos, participación política, violencia contra la mujer, y salud sexual y reproductiva. Evidencia de ello es el documento Diagnóstico de brecha de género en Santander (2009), donde se realizó un estudio exploratorio de las diferencias de género que fue la base para el Plan decenal de igualdad de oportunidades sobre la mujer 2010-2019, comprendido en el Plan de Desarrollo Santander Incluyente 2008-2011.

Aunque se reconoce que es necesario promover la inserción equitativa en el mercado laboral para hombres y mujeres, poco se conoce sobre el mercado laboral en la región santandereana y sobre los factores que determinan el salario de los trabajadores. Por tanto, el objetivo de este artículo es analizar los factores que inciden en los niveles salariales y en sus diferencias por género para el departamento de Santander en el periodo comprendido entre 2012 a 2014, usando como fuente de información la base de datos de la Gran Encuesta Integrada de Hogares (GEIH). De forma análoga, se busca establecer la posible existencia de discriminación salarial que atribuya las diferencias en ingresos laborales a factores no observables para la población santandereana. En consecuencia, los resultados obtenidos en este trabajo pueden servir como referente para investigaciones que amplíen los alcances de este estudio, o bien, como evidencia para la implementación de mejoras en materia de política pública.

Para ello, el documento se ha dividido en cinco secciones. En la primera se resume la literatura teórica y empírica acerca de los determinantes y diferencias salariales, en el marco de la teoría del capital humano. En la segunda se expone la metodología implementada para la determinación salarial y sus diferencias, explicando las ecuaciones de ingreso tipo Mincer y la descomposición Blinder-Oaxaca (BO), incorporando simultáneamente el uso de corrección de sesgo de selección de Heckman (1979) para la muestra; igualmente se describen los datos utilizados para el análisis empírico. En la tercera sección se efectúa un análisis descriptivo del mercado laboral en Santander durante 2012-2014. Los resultados del análisis econométrico se presentan en la sección cuatro. Finalmente se exhiben las conclusiones y recomendaciones de política.

\section{ANTECEDENTES TEÓRICOS Y EMPÍRICOS}

\section{La teoría neoclásica del capital hu- mano, salarios y género}

El estudio de los determinantes del ingreso salarial en el mercado laboral es 
tradicional en el análisis económico. La teoría del capital humano (TCH), postulada por Mincer (1958), Shultz (1961) y Becker (1962), entre otros, ha sido el referente por excelencia para la comprensión de los determinantes de ingresos laborales, que documenta la importancia de la inversión en capital humano, su rentabilidad y relevancia para el análisis de los ingresos laborales de aquellos individuos que optan por invertir en educación. En esta teoría, la educación se constituye como variable fundamental que afecta los ingresos laborales a través de sus efectos sobre la productividad. A su vez, factores como la edad, las habilidades cognitivas, la experiencia o la base familiar, coadyuvan a explicar la acumulación de capital humano, su impacto en el desempeño laboral y, por ende, en los ingresos de los individuos.

En este orden de ideas, el concepto de discriminación por género surge en este contexto como apéndice de estudios sobre diferencias salariales ${ }^{1}$. Sin embargo, no todo diferencial salarial es sinónimo de discriminación, ni toda discriminación se traduce en diferencias en salarios (Tenjo, Ribero \& Bernat, 2005). La discriminación ocurre cuando dos individuos con las mismas características económicas y habilidades, desempeñan las mismas labores pero con un pago salarial diferente $y$ este tratamiento está sistemáticamente relacionado con determinadas características no económicas de dichos individuos (raza, sexo, religión, etc.).

La incorporación del análisis económico a temas de género y salarios inicia cerca de 1930, donde aspectos como la tercerización del empleo y la asignación ocupacional, motivaron el estudio de las causas de las diferencias salariales entre hombres y mujeres, como también trabajos sobre la producción doméstica y el uso del tiempo en las décadas de 1960 y 1970 (Benería, 2004; Alcañiz 2012). Más aún, para 1918, la polémica de la determinación del monto salarial giraba en torno a condiciones de competencia imperfecta. Sin embargo, este enfoque fue reemplazado por el análisis de competencia perfecta en el interior de modelos neoclásicos de discriminación. Así, tras la Segunda Guerra Mundial, trabajos llevados a cabo por Becker (1962) sobre la discriminación por gustos, y Arrow y Phelps (1972) sobre discriminación estadística, tomaron especial atención en la explicación de las diferencias salariales atribuidas a factores no observables, provenientes de la demanda de trabajo.

De acuerdo con Brizuela y Tumini (2008), la perspectiva feminista avanza en la explicación de las causas que producen la segmentación del

\footnotetext{
Según Benería (2004), con el surgimiento del movimiento feminista, la gran mayoría de los economistas que trabajaban los temas de mujeres continuaron utilizando los modelos neoclásicos u otras variaciones de los
} modelos convencionales. 
mercado y los pagos diferenciales por género. En su línea de estudio se analizan los estereotipos de género (positivos o negativos) que se establecen en la sociedad y se transportan a las ocupaciones, sean atributos positivos de las mujeres asociados al cuidado, salud, educación, ocupaciones administrativas, etc., y otros atributos negativos en relación con la adjudicación en cargos jerárquicos y de calificación técnica y profesional. Como consecuencia de lo anterior, los roles de género han jugado un papel apremiante en la estimación de los montos salariales, y la relación entre el género y los salarios ha contado con gran acogida. Para efectos de la presente investigación se tomará como base la teoría del capital humano, iniciada a fines de los años sesenta, en donde las características productivas de hombres y mujeres explican sus diferencias en participación e ingreso laboral.

\section{Determinantes de las diferencias en los ingresos salariales}

Como se mencionó en el apartado anterior, a partir de la segunda mitad del siglo XX se constituye la llamada teoría del capital humano como principal instrumento teórico y conceptual en el análisis de los determinantes de las rentas salariales. Análogamente, la TCH toma en cuenta otros factores acumuladores de capital humano que tienen que ver con las características personales del individuo. De esta forma se destacan los diferentes tipos de factores o variables, o ambos, que influyen en el nivel salarial individual, incorporando variables propuestas de entorno laboral, como los puestos de trabajo, tamaño de la empresa, antigüedad en la empresa, entre otras. En esta sección se resumen las principales variables que la evidencia empírica nacional e internacional señala como determinantes de los ingresos salariales.

\section{Características individuales y de ca- pital humano}

De acuerdo con el modelo neoclásico de capital humano (Becker, 1964), la inversión en educación incide positivamente en el salario; las decisiones de los individuos por tener un mayor nivel de formación generan una mayor productividad laboral esperada y, por tanto, es de esperarse que los ingresos aumenten de acuerdo con el nivel de escolaridad. Una vasta evidencia empírica apoya esta hipótesis de correlación positiva entre educación y salarios (Carrasco, 2001; Contreras \& Gallegos, 2011; Correa, Viáfara \& Zuluaga, 2010; De la Rica \& Ugidos, 1995; Guataquí, García \& Rodríguez, 2009; Korkeamäki \& Kyyrä, 2006; Kunze, 2005; Machin \& Poani, 2003; Varela et al., 2010).

Sin embargo, en relación con brechas de género parece no presentarse el mismo patrón, pues trabajos como el de Atal, Ñopo y Winder (2009), para varios países de América Latina, muestran que si bien las mujeres en promedio tienen un 
mayor nivel educativo que los hombres, ellas reciben un salario inferior; es decir, los retornos a la educación no se valoran de forma similar. Específicamente, en dicho estudio se encontró que los hombres ganan en promedio $10 \%$ más que las mujeres, a pesar de sus menores logros educativos; lo que más sorprende es que si las mujeres tienen las mismas características que los hombres (en particular el mismo nivel de educación), la brecha salarial entre géneros salta a casi el $20 \%$, aunque los resultados difieren entre países. Resultados similares se encontraron para Argentina (Esquivel, 2007) y Colombia (Tenjo \& Herrera, 2009). Este fenómeno usualmente es atribuido a prácticas discriminatorias que subvaloran el rol productivo de la mujer. Por su parte, Badel y Peña (2009) encuentran que los retornos a la educación en Colombia se comportan en forma de "U", afectando en mayor medida los salarios más bajos "pisos pegajosos" y los más altos "techos de cristal".

La edad también es una característica de importancia en la determinación de los salarios individuales. De acuerdo con la evidencia empírica, la edad genera efectos no lineales en el salario (Hernández, 1995; Varela et al., 2010); es decir, a medida que la edad aumenta, el salario se incrementa pero cada vez en menor medida, llegando incluso a un punto donde el aumento de la edad puede generar disminución en el salario. Atal et al. (2009) encuentran que la brecha salarial de género aumenta con la edad, lo cual podría explicarse por un efecto de cohorte o por el efecto de algunos rasgos no observables, como la experiencia. Por su parte, la experiencia es un factor de capital humano con efectos análogos a la edad. De acuerdo con los planteamientos del capital humano, a medida que aumenta la experiencia, el salario va aumentando, pero en proporción cada vez más baja. Drolet (2001), por ejemplo, muestra que la experiencia explica la brecha salarial en 12 $\%$ aproximadamente para el caso canadiense, similar a lo que evidencian investigaciones posteriores (Actis \& Atucha, 2003; Contreras \& Gallegos, 2011). De modo similar, Kunze (2005) observa el nivel de ingresos en varios niveles de experiencia en Alemania, y encuentra una brecha salarial considerable en el primer empleo, la cual permanece constante a lo largo de la carrera; análogamente, la autora determina que existen problemas de segregación ocupacional por género en contra de las mujeres. De acuerdo con ello, las diferencias salariales se asocian principalmente a un componente explicado, es decir, la educación y experiencia como determinantes de capital humano juegan un papel apremiante. Por otra parte, Hernández (1995) percibe que a medida que aumenta el tiempo de permanencia en el último empleo, la relación con el salario se hace más positiva, favoreciendo principalmente a las mujeres. Esta evidencia apoya la hipótesis de que el empleo sin interrupciones voluntarias mitiga los procesos de discriminación 
en salarios, en concordancia con Witkowska (2013), quien realiza un estudio similar para Estados Unidos.

\section{Características del empleo}

El tipo de ocupación es un factor del mercado laboral que influye en gran medida sobre el monto salarial, puesto que usualmente se relaciona con el problema de segregación ocupacional, en donde hombres y mujeres son asignados a determinadas ocupaciones dependiendo de características específicas del empleo, como el nivel de educación, habilidades cognitivas, esfuerzo físico, etc. (Amarante \& Espino, 2004; Cain, 1986). Hernández (1995); Korkeamäki \& Kyyrä (2006) y El-Hamidi y Said (2014) encuentran que existen amplias diferencias en salarios entre trabajadores directivos y administrativos, debido a la concentración desproporcionada de mujeres en puestos de trabajo de salarios bajos, en gran parte atribuible a la menor habilidad y los complejos requisitos del trabajo y hechos discriminatorios. Así, los puestos de directivos donde la remuneración es elevada están siendo ocupados principalmente por la población masculina (Esquivel, 2007; Baquero, 2001). Empero, Tenjo y Herrera (2009), en su estudio realizado para Colombia, hallaron que en el caso de las mujeres la estructura ocupacional las favorecía, ya que las mujeres están más concentradas que los hombres en las ocupaciones de niveles de calificación mayor y por ende de mayores salarios. Sin embargo, existen casos en los que tanto hombres como mujeres poseen las mismas características para llevar a cabo determinada ocupación y son los hombres los que reciben salarios superiores; ejemplo de ello es el trabajo de Urdinola y Wodon (2003), donde la masificación de la oferta laboral lleva a que las mujeres sean retribuidas con salarios inferiores, aun en puestos de trabajo mejor pagados.

Por otra parte, de acuerdo con la teoría estructuralista del mercado de trabajo, el tamaño de la empresa se relaciona con el poder de mercado, la educación, la formación de los trabajadores y el uso de tecnologías. Dado lo anterior, el capital físico de una empresa se encuentra estrechamente relacionado con el capital humano de sus empleados y, por ende, la productividad de la empresa. En Colombia, la investigación realizada por Ortiz, Uribe y García (2007) muestra diferenciales de ingresos significativos entre el sector formal (primario) e informal (secundario), por lo que el tamaño de la planta incide positiva y significativamente en los ingresos. Más aun, los autores concluyen que la omisión del tamaño de la planta como determinante del ingreso, sesga positivamente los impactos de la educación, experiencia, jefatura del hogar y el género en el pago salarial.

En la misma línea, de acuerdo con el enfoque estructuralista, un mercado de trabajo formal sugiere mejores pagos, debido a que cuenta con condiciones y características de mejor calidad (Uribe 
\& Ortiz, 2006). Según Piore (1970) y Cain (1986), la segmentación del mercado se ve íntimamente relacionada con procesos discriminatorios en contra de las minorías poblacionales; estos autores encuentran que las mujeres o individuos afrodescendientes están destinados al mercado secundario de trabajo. Deininger, Jin y Nagarajan (2013), en su estudio realizado al mercado laboral informal de la India, muestran que la discriminación salarial por género es mayor en los mercados informales que en los formales, por lo que las pérdidas debidas a la discriminación son mayores a los beneficios adquiridos por la puesta en marcha de políticas de mitigación.

\section{Características familiares}

Las características familiares se componen de factores que de alguna u otra manera inciden sobre las decisiones del individuo en lo concerniente a su participación en el mercado de trabajo y la aceptación de determinados montos salariales como pago. Fernández (2006) argumenta que existen factores, en el interior de las familias, que sirven como señales del compromiso por hacer parte del mercado laboral. Becker (1985) ilustra que las mujeres tienen una mayor responsabilidad por el cuidado de los niños y que la realización de las tareas puede inducir a la exclusión de ellas en trabajos más exigentes, así como a dedicar menos esfuerzo para hacer el mismo trabajo que los hombres. En tal sentido, la tenencia de hijos es un factor familiar asociado al rol de género de los individuos en el hogar. Esta variable es fundamental tanto para la determinación del acceso al empleo como para los ingresos salariales, pues una persona con hijos tiene mayor necesidad de obtener un empleo que supla sus necesidades y las de su familia.

Blau y Kahn (2000) hallan evidencia de que las mujeres siguen siendo las principales responsables de las tareas domésticas y el cuidado de los hijos en la mayoría de las familias norteamericanas y que, por tanto, perciben salarios más bajos. De acuerdo con Tenjo, Ribero y Bernat (2005), para los empleadores la tenencia de hijos es un factor de riesgo e incertidumbre en las decisiones en relación con la contratación de mujeres, por lo cual terminan penalizándolas con menores salarios. En la misma línea, Fernández (2006) estima que las labores que desempeñan las mujeres en el hogar, disminuyen la posibilidad de trabajar horas extras, sin embargo, al analizar con cuidado se observan comportamientos muy disímiles según el punto de la distribución de los ingresos en el que se analice el fenómeno.

El estado civil de un individuo implica su responsabilidad en los roles del hogar, es por ello que los resultados con respecto al efecto del estado civil son diversos dentro de la evidencia empírica. De acuerdo con Fernández (2006), es de esperarse que estar casado o en 
unión libre esté asociado con retornos positivos y significativos tanto para hombres como mujeres, así, los empleadores pueden percibir la vida en pareja como una señal de compromiso y constancia de la persona o en la medida en que estas tengan mayores incentivos a esforzarse en el trabajo y ascender para mejorar el nivel de vida del núcleo familiar. Abadía (2005) encuentra resultados que apoyan la hipótesis de que los empleadores discriminan estadísticamente por género a las mujeres casadas o en unión libre en el mercado laboral colombiano; esto debido, posiblemente, a que las mujeres deben dividir su tiempo entre las tareas del hogar y el trabajo, por lo que el empleador crea estereotipos en el acceso y pago del empleo.

Este trabajo explora el efecto de estas características personales, familiares y del empleo sobre los salarios de hombres y mujeres en Santander. De manera tal, se indaga principalmente por los efectos diferenciadores que puedan tener sobre cada grupo poblacional y sobre la posible existencia de discriminación salarial por género. Para alcanzar este objetivo, la próxima sección resume la metodología que se utiliza.

\section{ASPECTOS METODOLÓGICOS}

\section{Ecuaciones mincerianas de ingreso}

De acuerdo con el análisis de las relaciones existentes entre las variables explicativas y los salarios, se hace uso de dos ecuaciones tipo Mincer (1974)2: la primera de ellas para la población masculina y la segunda para la población femenina. En estas ecuaciones se consideran las dimensiones de capital humano, base familiar, así como variables del empleo. Es decir, el salario (con notación logarítmica) se expresa en función de una serie de características observables, como sigue:

$$
\ln \left(Y_{i}\right)=X_{i} \beta+\sigma_{\lambda} \lambda_{i}+\varepsilon_{i}
$$

Donde $Y_{i}$ es el ingreso por hora del trabajador $i, X_{i}$ es un vector de características observables que miden el capital humano del trabajador $i, \beta$ es un vector de parámetros asociados que

\footnotetext{
Si bien la estimación minceriana por mínimos cuadrados ordinarios (MCO) ha contado con gran acogida, dicha estimación no se encuentra absuelta de problemas (Blaconá et al., 2001). De acuerdo con las teorías de señalización (Spence, 1973; Arrow, 1973) y estudios como los de Griliches (1977) y Willis (1997), en la medición del rendimiento de la educación por el método MCO existen varios sesgos. Se pueden presentar problemas de selección muestral que suelen corregirse con el procedimiento propuesto por Heckman (1979) y usado en este documento, o problemas de endogeneidad, asociados al inconveniente de identificar las habilidades de las personas, entendidas como características que bien podrían considerarse dotaciones, y que podrían llevar a estimaciones inconsistentes y sesgadas. Para superar la endogeneidad se acude a la corrección por variables instrumentales (véanse Hausman \& Taylor, 1981). En la mayoría de los casos se usa la información sobre el nivel educativo de la madre o el padre para corregir dicho problema; sin embargo, en la GEIH no se cuenta con dicha información y no es posible implementar la mencionada corrección.
} 
representa los retornos de los distintos tipos de capital humano, $\lambda$ es el término de corrección de sesgo, $\sigma_{\lambda}$ la covarianza entre los factores inobservables que afectan a la participación laboral y aquellos que influyen en el salario y $\varepsilon_{i}$ es un término de perturbación aleatoria. La variable $\lambda$ y su respectivo parámetro $\sigma_{\lambda}$ se incluyen como corrección del sesgo de selección propuesto en Heckman (1979), el cual genera la aleatoriedad de la ecuación de salarios a partir de un modelo probit de participación en el mercado laboral. Descomposición Blinder-Oaxaca

Siguiendo a Fernández (2006), es posible afirmar que existen fuerzas detrás del fenómeno de las diferencias salariales que hacen de este proceso un componente clave para análisis, diseño y puesta en marcha de políticas de ataque. Por tanto, usualmente se establece una descomposición de la ecuación de Mincer para hombres y mujeres, como sigue:

$$
\begin{gathered}
\ln \left(Y_{m}\right)=X_{m} \beta+\sigma_{\lambda} \lambda_{m}+\varepsilon_{m} \quad[2 \mathrm{a}] \\
\ln \left(Y_{h}\right)=X_{h} \beta+\sigma_{\lambda} \lambda_{h}+\varepsilon_{h} \quad[2 \mathrm{~b}]
\end{gathered}
$$

Donde $h$ y $m$ expresan los términos correspondientes a hombre y mujer, respectivamente. La metodología sugerida por Blinder y Oaxaca (1973) es fundamental para el análisis de descomposición del diferencial salarial entre un componente que se debe a diferencias en dotaciones de capital humano entre sexos y otro componente que se debe a retornos de dichas dotaciones. Siguiendo a Tenjo (1993), el diferencial estimado se puede expresar como la suma de diferentes componentes, a saber:

$$
\begin{gathered}
\ln \left(Y_{h}\right)-\ln \left(Y_{m}\right)=\left(X_{h}-X_{m}\right) \beta_{h}+X_{m} \\
\left(\beta_{h}-\beta_{m}\right)+\left(\sigma_{\lambda} \lambda_{h}-\sigma_{\lambda} \lambda_{m}\right) \quad \text { [3] }
\end{gathered}
$$

Donde, $\ln \left(Y_{h}\right)-\ln \left(Y_{m}\right)$ es el término que enuncia la diferencia salarial, en términos logarítmicos, entre hombres y mujeres.

$\left(X_{h}-X_{m}\right) \beta_{h}$ es la parte explicada por las diferencias en características productivas de los trabajadores. Esta podría ser una medida de discriminación pero en el acceso a determinada variable, por ejemplo la educación.

$X_{m}\left(\beta_{h}-\beta_{m}\right)$ es la parte explicada por discrepancias en coeficientes. Es decir, expresa un tratamiento distinto para cada grupo de estudio o medida de discriminación salarial, pues los parámetros resumen las reglas que usa el mercado para valorar las cantidades de capital humano de los trabajadores. Por lo tanto, si estas reglas son diferentes, sugieren un tratamiento discriminatorio del mercado en términos salariales.

$\left(\sigma_{\lambda} \lambda_{h}-\sigma_{\lambda} \lambda_{m}\right)$ es el componente asociado a diferencias entre el patrón de incorporación al mercado laboral entre los hombres y las mujeres. 


\section{Datos de estudio}

La base de datos utilizada corresponde a la Gran Encuesta Integrada de Hogares (GEIH), recolectada por el Departamento Administrativo Nacional de Estadística (DANE), para los años 2012 a 2014. Los datos de ingresos salariales se encuentran a precios constantes de diciembre de 2012.

Se considera como población objetivo la muestra de los datos de cabecera y resto correspondiente al departamento de Santander y, dentro de esta, la población económicamente activa (PEA) entre los 18 a 60 años $^{3}$. La muestra implementada se compone de 14373 observaciones para el año 2012, de las cuales el 54,52\% corresponde a los hombres y el $45,48 \%$ a las mujeres. Para el año 2013 el número de observaciones pasó a 14344; finalmente para el año 2014 fueron 14187 observaciones, para las cuales ninguna de las variables en estudio presenta valores perdidos.

\section{ANÁLISIS DESCRIPTIVO DEL MERCADO LABORAL EN SANTANDER, 2012 - 2014}

De acuerdo con los datos de la GEIH, en Santander la tasa global de participación (TGP), como relación entre la población económicamente activa (PEA) y la población en edad de trabajar (PET), registró un nivel de 68,9 $\%$ en 2014 frente al $69,1 \%$ presentado en 2012, lo cual corresponde a una pequeña reducción en 0,2 puntos porcentuales. Por otra parte, la tasa de ocupación (TO) mostró un comportamiento contrario a la TGP, esto es, la TO fue de $64,4 \%$ en comparación al $63,7 \%$ de 2012, en tanto que la tasa de desempleo (TD) se redujo gradualmente hasta en 1,3 puntos.

En Santander estos indicadores laborales no presentaron mayores cambios entre 2012 y 2014. De cualquier modo, los resultados reflejan que los mayores indicadores de participación laboral son para la población masculina; con TGP superiores a $78 \%$ frente a $60 \%$ en las mujeres, tal como lo muestra la Figura 1. El mismo comportamiento presentan las tasas de ocupación y desocupación con brechas aproximadas de $20 \%$ y $4 \%$, respectivamente. Esto refleja, no solo un contexto favorecedor para la población masculina, sino también la invariabilidad de la estructura del mercado laboral en términos de ocupados y desocupados por género durante el periodo de análisis.

Entretanto, los indicadores de población reflejaron incrementos importantes. La

\footnotetext{
Se toma este intervalo de edad siguiendo el artículo 35 de la Ley 1098/06, que comprende este rango para poder laborar sin ninguna inspección de trabajo, adicional a la edad promedio de jubilación para hombres y mujeres.
} 
Diferencias salariales por género en el departamento de Santander - Colombia

Alexandra Cortés Aguilar • María Alejandra Flórez Vera

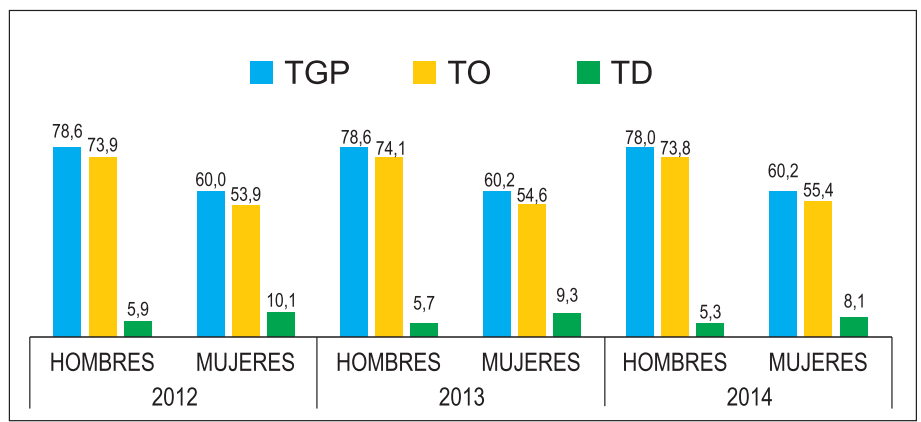

Figura 1. Indicadores de mercado laboral en Santander por género Fuente: elaboración propia con base en Departamento Administrativo Nacional de Estadística DANE, Gran Encuesta Integrada de Hogares (GEIH) 2012-2014.

población total y en edad de trabajar (PET) ascendió aproximadamente en veinte mil y veintiséis mil personas respectivamente de 2012 a 2014; no obstante, el incremento de la PET apenas supera el punto porcentual en variabilidad. En la región santandereana, para el periodo de estudio, la población ocupada alcanzó niveles del $93 \%$ como proporción de la PEA en el 2014, tal como se observa en la Tabla 1.

Tabla 1. Indicadores de población en el mercado laboral santandereano (Dane, 2013)

\begin{tabular}{|c|c|c|c|}
\hline Concepto & 2012 & 2013 & 2014 \\
\hline Población total & 2.031 & 2.041 & 2.051 \\
\hline Población en edad de trabajar & 1.641 & 1.654 & 1.667 \\
\hline Población económicamente activa & 1.134 & 1.145 & 1.149 \\
\hline Ocupados & 1.046 & 1.061 & 1.074 \\
\hline Desocupados & 88 & 84 & 75 \\
\hline
\end{tabular}

Fuente: elaboración propia con base en Departamento Administrativo Nacional de Estadística DANE, Gran Encuesta Integrada de Hogares (GEIH), datos en miles.

En términos de la muestra de estudio, de 2012 a 2014 la población masculina ocupada fue de $53,96 \%$ en promedio, y el restante 46,03\% corresponde a población femenina ocupada. Dichas cifras indican que la participación femenina en el mercado laboral se ha incrementado, en comparación a lo que reflejan las cifras de 2005, donde la población femenina, como proporción de la población ocupaba, alcanzaba niveles máximos del $20 \%$; el restante $80 \%$ correspondía a los hombres ocupados, comportamiento que se 
replica para la mayoría de los rangos de edad (PPMIGS-PS, 2010, p. 23).

Con respecto a los ingresos mensuales de la población, en el Anexo A se presentan las estadísticas descriptivas para hombres y mujeres para los años 2012-2014. Al respecto, se observan claras diferencias en el salario mensual promedio entre hombres $(\$ 1.090 .832,7)$ y mujeres $(\$ 807.485,8)$. Aunque esta diferencia no expresa necesariamente que se trate de discriminación salarial, este es un primer indicador de que efectivamente hay un trato diferencial para hombres y mujeres en el interior del mercado laboral santandereano. Los resultados para los ingresos por hora presentan comportamientos similares. Durante los tres años, en promedio, las mujeres reciben el $89,28 \%$ del salario que se otorga a los hombres. Una posible explicación a este comportamiento se respalda en el tiempo que dedican los hombres a trabajar durante la semana en comparación a la dedicación de las mujeres. Más del $90 \%$ de los hombres son trabajadores de tiempo completo, es decir, ocupan 40 horas o más de la semana para desempeñar determinada actividad, contrastando con un aproximado de $71 \%$ de mujeres trabajadoras de tiempo completo.

No se encontraron divergencias estadísticamente significativas en la edad promedio entre hombres y mujeres; en ambos grupos, la edad media es de 37 años. Sin embargo, en términos de educación (medida como años de escolaridad), se observa que en promedio las mujeres tienen un año más de educación que los hombres (9 años para los hombres y 10 años para las mujeres). Ahora bien, las mujeres ocupan la mayor proporción de su población en el nivel de educación superior, mientras los hombres son mayoría en el nivel primaria; por lo que se esperaría que ellas reciban mayores ingresos salariales en términos de retornos a la educación.

En términos ocupacionales, la estructura del mercado laboral no presentó cambios significativos durante el tiempo analizado. La mayoría de la población está empleada en empresas, o bien como trabajadores de cuenta propia, esencialmente en las microempresas. Las mayores brechas se observan en la población ocupada en oficios domésticos, jornaleros y empleadores; puesto que la primera está siendo principalmente designada a la población femenina y las dos restantes a la población masculina. Esto podría significar segregación ocupacional, con los hombres principalmente destinados a cargos como jornaleros (menores salarios) y empleadores (mayores salarios), mientras las mujeres se ocupan principalmente en cargos definidos de acuerdo con estereotipos y roles de género en el sector servicios.

Entre los resultados más sobresalientes se destaca que las mujeres presentan la mayor participación en la ocupación 
de empleado doméstico con un $97 \%$ en promedio. Por su parte, el porcentaje de participación de hombres supera al de las mujeres en las ocupaciones empleador y jornalero con un $71,1 \%$ y $89,4 \%$ respectivamente. Indistintamente, tal como se observa en la Figura 2, en la mayoría de ocupaciones las mujeres perciben salarios en promedio inferiores a los recibidos por los hombres; empero, en la ocupaciones de empleado doméstico y empleado público las mujeres reciben mayores ingresos, aunque esta diferencia no supera los cincuenta mil pesos. Las ocupaciones que concentran mayor nivel de ingreso promedio son empleado público y empleador, donde las diferencias tanto en participación como en ingreso son más significativas. De manera que los hombres obtienen una proporción mucho más alta del ingreso respecto a las mujeres, esto es, en promedio los hombres ocupados como empleadores ganan \$251.391 más que las mujeres.

Por otra parte, se infiere la existencia de segmentación laboral en la región santandereana, ya que en el caso particular de los hombres, estos son asignados a determinadas ramas de la actividad económica (principalmente a empleos como obreros, cuenta propia o empleadores, en donde los últimos ostentan salarios muy superiores al resto de la población), debido a que sus características les permiten desempeñarse en actividades de mayor esfuerzo y riesgo ${ }^{4}$. En tanto que las mujeres se encuentran principalmente ubicadas en actividades de servicios domésticos y cargos públicos, es decir, ocupaciones que van de la mano con

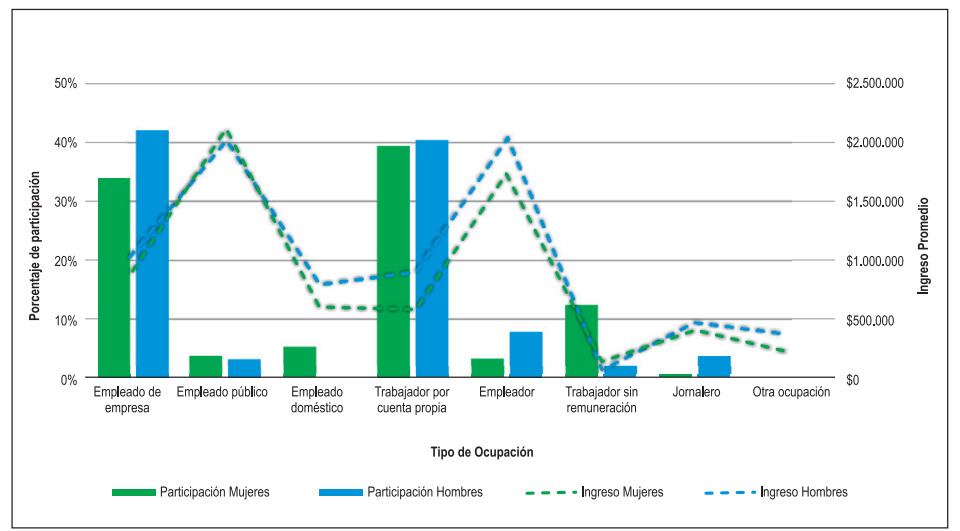

Figura 2. Estructura ocupacional del mercado laboral santandereano en términos de ingreso promedio y sexo, año 2014

Fuente: elaboración propia con base en Departamento Administrativo Nacional de Estadística DANE, Gran Encuesta Integrada de Hogares GEIH (2014).

4 De ahí que se pueda establecer la posible existencia de brechas salariales debidas a diferencias compensatorias. 
su rol de género. Todas las estadísticas descriptivas de estas variables se presentan en el Anexo B.

\section{RESULTADOS ECONOMÉTRI- COS}

\section{Resultados de las estimaciones min- cerianas}

En términos generales, los signos de los coeficientes coinciden con lo esperado de acuerdo con la revisión de la literatura previa. El Anexo C presenta las tablas con los resultados de las estimaciones econométricas. Controlando por características personales, familiares y del empleo, para el periodo de estudio, el diferencial promedio de ingresos pasó de $23,7 \%$ en 2012, 22,8 \% en 2013 a $20,7 \%$ en 2014, es decir, las brechas en el ingreso promedio presentaron un comportamiento descendente, aunque es la población masculina la beneficiada por este diferencial.

Ahora bien, examinando los determinantes del ingreso por género, las ecuaciones mincerianas de salarios presentan coeficientes de signos que son equivalentes a los propuestos por la teoría del capital humano, donde la experiencia, la edad y la educación ejercen efectos positivos sobre el salario. Es decir, controlando por las demás variables, por un año más de educación en 2012 un hombre y una mujer en promedio ven aumentar su salario en $7,7 \%$. Sin embargo, la valoración que hace el mercado a un año más de escolaridad fue tomando discrepancias para los años de estudio como se refleja en 2013, e incluso para 2014 donde por un año más de educación de un hombre su salario aumenta 7,0 \% frente al aumento en las mujeres de tan solo $6,1 \%$ en su ingreso. Estos resultados son similares a la evidencia empírica nacional (Tenjo, Ribero \& Bernat, 2005; Tenjo \& Herrera, 2009; Badel \& Peña, 2009), a pesar de la mejora en los últimos años, en el nivel educativo de las mujeres en Santander. Según la evidencia presentada se puede inferir que, controlando por las demás variables de capital humano y del empleo, el mercado laboral en Santander está perdiendo la connotación de un proceso de valoración de la escolaridad equitativo de acuerdo con la inversión en educación que efectúan los individuos.

Ahora bien, la incidencia de la edad en el ingreso es positiva tanto para hombres como mujeres. La población masculina se ve más favorecida que la femenina, ya que sus ingresos van en aumento al pasar sus años de vida hasta los 50 años en 2012, pasando a 71 años en 2014. Aunque el comportamiento, en el caso de las mujeres, es similar, estas tienen incrementos en los ingresos solo hasta los 46 años de edad en 2012 y hasta los 50 años en 2014.

Por su parte, la experiencia, medida como los años de antigüedad en la empresa, para 2012 y 2014 muestra que tanto hombres como mujeres ven 
aumentar sus ingresos hasta niveles de experiencia por encima de los 13 años. No obstante, en 2012 se presentan las mayores divergencias, pues para los hombres el aumento de su ingreso es asegurado hasta niveles de experiencia que alcanzan los 28 años frente a los 18 años requeridos a las mujeres. Sin embargo, esta discrepancia se revierte para el año 2014, ya que los hombres requieren de niveles de experiencia de hasta 14 años para que el aumento de sus ingresos se siga asegurando, en tanto que las mujeres pueden esperar aumentos por tres años más que sus pares masculinos, es decir, sus ingresos pueden verse aumentados hasta un nivel de experiencia de 17 años. Lo anterior indica, particularmente entre 2012 y 2014, que la relación entre el nivel de experiencia y los ingresos va favoreciendo a las mujeres; puesto que ellas pueden ver aumentar sus salarios inclusive por más tiempo que los hombres mediante el cumplimiento de mayores años de antigüedad en la empresa. Estos resultados apoyan la hipótesis de que el mercado laboral premia la no interrupción voluntaria del trabajo, aplicada en Hernández (1995) y Witkowska (2013), por lo cual se esperaría que mayores niveles de experiencia incidan de forma positiva sobre el salario de las mujeres.

Con respecto a las variables del entorno laboral, la condición de informalidad de un individuo incide negativamente sobre el nivel de su salario, hallazgo que corresponde con la evidencia empírica tanto nacional como internacional. Así, se observa que la informalidad es un fenómeno que castiga con mayor peso el ingreso de las mujeres que el de los hombres. En otras palabras, las mujeres pueden verse mayormente afectadas por la no correspondencia entre la oferta y demanda de mano de obra y los altos costos laborales en que incurren las empresas al contratar personal de manera formal, entre otros factores que se encuentran dentro de esta problemática.

Ahora bien, bajo el enfoque estructuralista del mercado, el tipo de ocupación de los individuos trae consigo ciertas características, buenas o malas, que inciden sobre el nivel de salarios que devenga la población trabajadora. En el presente documento se examinaron los diferentes tipos de ocupación dados por el DANE, tomando como categoría base empleado de empresa privada. Así, controlando por la demás variables, se observa que los trabajadores por cuenta propia ostentan salarios inferiores a los empleados de empresa, especialmente la población femenina; lo anterior refleja que los cuenta propia en Santander pueden ser en su mayoría la población dedicada a la venta ambulante u oficios que no cuentan con las prestaciones sociales y otros beneficios, por lo que su trabajo implica mayor esfuerzo y menor nivel salarial. Ahora bien, en cargos como empleado público y empleador, el salario es significativamente superior al de un empleado de 
empresa; en dichas ocupaciones son las mujeres las que ostentan mayores salarios en comparación con sus pares en empresas, este aumento oscila entre $35 \%$ a $55 \%$, mientras que el aumento salarial para los hombres como empleado públicos se encuentra entre el $10 \%$ y $18 \%$ y como empleadores entre $33 \%$ y $55 \%$. Como dato particular, ser empleado doméstico tan solo presenta brechas salariales estadísticamente significativas para las mujeres, pues como ya se hizo evidente, son estas las que ocupan principalmente este tipo de cargos. Entretanto ser jornalero no presenta diferencias estadísticamente significativas en el ingreso con los empleados de empresa tanto para mujeres como para hombres.

Asimismo, bajo el estructuralismo, el tamaño de la empresa incide de forma positiva sobre el nivel de ingresos de la población. Para las estimaciones se tomó como categoría base la empresa grande. Se encontró que las brechas en el ingreso se van reduciendo a medida que el tamaño de la empresa va en aumento, dicho aumento se presenta principalmente en las mujeres, es decir, un tamaño mayor de la empresa induce a mejores condiciones laborales y mayores niveles de entrenamiento y productividad, por lo que los ingresos se encuentran en aumento, controlando por las demás variables.
En resumen, los determinantes incorporados para este estudio contaron con los signos esperados, con ciertas particularidades desde el punto de vista del sexo de los individuos. Variables como la experiencia y el tamaño de la empresa favorecen principalmente a las mujeres, dado el proceso de entrenamiento y capacitación de estas. Por otra parte, la educación y edad son factores a favor de la población masculina; además la informalidad penaliza en menor grado el salario de los hombres que el de las mujeres, dadas las características detrás de la informalidad, que puede ser afrontada en mayor medida por los hombres. Además, los coeficientes de los tipos de ocupación corresponden a la teoría bajo el enfoque estructuralista, ya que de acuerdo con las condiciones y requisitos que trae consigo cada ocupación se determina el monto salarial por devengar. No obstante, la evidencia en Santander refleja que un "cuenta propia" ostenta salarios inferiores a un empleado de empresa, pero cercanos a los de un jornalero; lo que muestra las precarias condiciones a las que se somete la población ubicada en este tipo de oficio.

\section{Corrección de selectividad y deter- minantes de la participación laboral por género}

La población masculina que se encuentra por fuera del mercado laboral

El parámetro que acompaña a lambda, mostró ser significativo únicamente para la población masculina. 
tiene un salario de reserva mayor ( 33 $\%$ en 2012 hasta $43,4 \%$ en 2014) al que les ofrece el mercado laboral ${ }^{5}$. Este hecho es contrario al presentado en la población femenina donde los resultados de este parámetro indican que las mujeres desocupadas están dispuestas a aceptar cualquier monto salarial que el mercado de trabajo esté dispuesto a ofrecerles. Lo anterior refleja que detrás de la aceptación, o no, de un determinado monto salarial existen factores que inciden sobre la decisión de hombres y mujeres. Para el caso santandereano dichos factores pesan con mayor fuerza sobre las mujeres, presionándolas a estar dispuestas a aceptar el ingreso que el mercado les ofrezca por su trabajo. Para examinar este fenómeno, en este estudio se siguió a Bernat (2005), tomando como factores determinantes de la participación en el mercado de trabajo características personales como la edad, años de escolaridad y asistencia escolar, así como características familiares como la jefatura del hogar, estar casado o en unión libre y la tenencia de menores de 6 años en el hogar como proxy de hijos. Dado que en este punto se toma como metodología de estudio un probit de participación, los efectos marginales sobre la probabilidad de trabajar, surgidos a partir de los cambios en la magnitud de las variables explicativas, se presentan en el Anexo D.

En términos generales, los resultados corresponden a los planteamientos de la nueva economía doméstica, sobre la distribución del tiempo entre el hogar y el trabajo. De esta forma, la tenencia de niños menores de 6 años en el hogar y estar casado o en unión libre, como indicadores de compromiso, reducen la probabilidad de participación en el mercado laboral de la mujeres, en tanto que aumenta la de los hombres; todo lo contario ocurre con un año más de escolaridad, lo cual propicia un aumento de la probabilidad de trabajar de la mujer y reduce de manera exigua esta probabilidad en los hombres santandereanos. Por su parte, la jefatura del hogar y la edad son factores que aumentan la probabilidad de participar en el mercado laboral tanto para hombres como para mujeres, especialmente para ellas. Finalmente, la asistencia a la escuela, o a cualquier institución educativa, hace que quienes se encuentren en esta situación tengan menores incentivos para participar del mercado laboral y, por ende, a ser contratado; sin embargo, en 2012 y 2014 la probabilidad de participación para los hombres es menor que para las mujeres, si se encuentran asistiendo a la escuela; entretanto en 2013 sus probabilidades de trabajar aunque negativas son similares. Lo anterior muestra como las variables familiares inciden de forma diferente para hombres y mujeres; incluso cuando ambos grupos se señalizan de igual forma, la percepción del mercado laboral valora de forma distinta. 


\section{Descomposición Blinder-Oaxaca: existencia de discriminación salarial por género}

De acuerdo con los resultados estimados con corrección de sesgo de selección, controlando por edad, experiencia, años de educación, tipo de ocupación y características laborales de informalidad y tamaño de la empresa, se observa que los hombres ostentan un ingreso salarial promedio más alto que el percibido por las mujeres santandereanas con iguales características productivas, el cual para 2012 fue de 21,52\%; brecha que se acrecienta en 2014 a niveles de 25,61 $\%$. Esta brecha en promedio es explicada en mayor medida por el componente no explicado, asociado usualmente a un factor discriminatorio que alcanza un $24,50 \%$ en 2012, el cual, al igual que el diferencial promedio, se va acentuando hasta 2014, llegando a $30,37 \%$. Dicho componente se debe a factores no observables en el mercado del trabajo o bien a una valoración distintivita de las cantidades de capital humano de los trabajadores. Bajo este supuesto, las mujeres dejan de recibir entre un $25 \%$ y $30 \%$ de salario en comparación con los hombres, aun cuando estas cuentan con las mismas cantidades de capital humano que sus pares. No obstante, como se indicó anteriormente, en Santander las mujeres tienen niveles de educación más altos, hecho que discrepa del fenómeno discriminatorio presentado, pues las mayores inversiones en educación deberían implicar reducciones tanto de la brecha en promedio como de discriminación salarial por género.

Dado lo anterior, las brechas salariales debidas a las características productivas favorecen el género femenino en Santander. Esto es, dadas las características de capital humano de las mujeres, si estas fuesen retribuidas con los mismos criterios con que se valoran las características de los hombres, las mujeres deberían recibir salarios promedio superiores. En términos numéricos, si las mujeres en la región santandereana vieran retribuidas sus inversiones en capital humano con los retornos percibidos por sus pares masculinos, deberían recibir un salario superior al que reciben los hombres en $4,38 \%, 3,53 \%$ y $2,11 \%$ en los años 2012 a 2014, respectivamente. Estas prácticas discriminatorias podrían deberse a la segmentación del mercado de trabajo (explicada por la masificación de la oferta laboral), en donde las mujeres se destinan a labores con peores pagos o bien, como se afirma en Piore (1970) y Cain (1986), están destinadas al mercado secundario de trabajo. Por otra parte, en Deininger, Jin y Nagarajan (2013) se encuentra otra razón asociada a la discriminación en ingresos, desde el componente de informalidad, el cual para el caso santandereano, como ya se hizo evidente, penaliza en mayor medida los ingresos de la población femenina. 


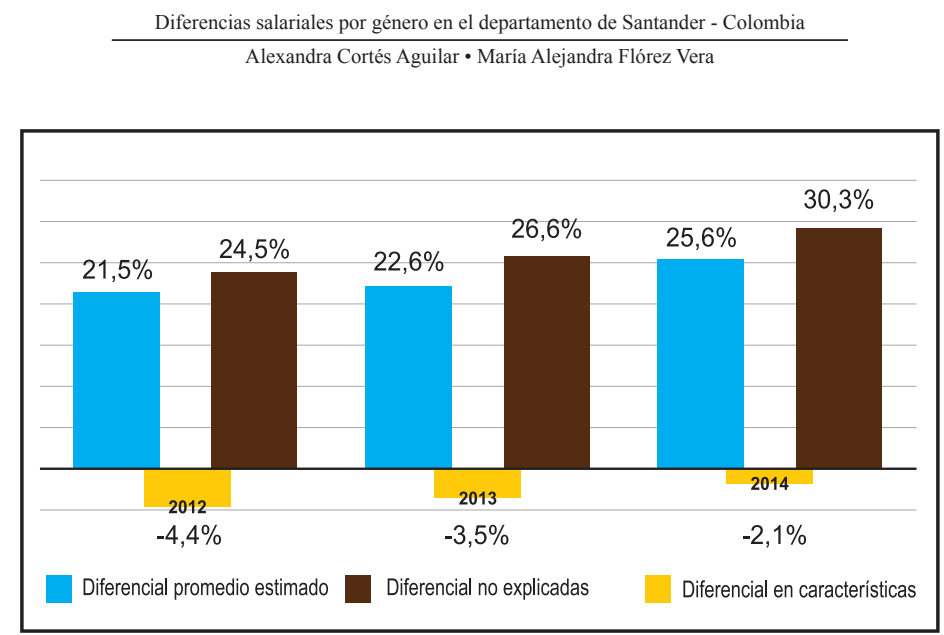

Figura 3. Descomposición Blinder-Oaxaca, de acuerdo con estimación de ingresos Fuente: elaboración propia con base en Departamento Administrativo Nacional de Estadística (DANE), Gran Encuesta Integrada de Hogares (GEIH), 2012-2014.

A partir de los resultados de las estimaciones de las ecuaciones mincerianas, y controlando por las variables de capital humano y del empleo, se concluye, en términos generales, que existe evidencia de que las mujeres del departamento de Santander son víctimas de discriminación salarial. Por el contrario, si las características observables únicamente determinaran la remuneración salarial de los individuos, las mujeres en Santander deberían recibir en promedio mayores ingresos laborales que los hombres. Estos resultados son imperantes en la medida en que presentan comportamientos similares a la realidad latinoamericana estudiada en Atal, Ñopo y Winder (2009), lo cual refleja la falta de correspondencia entre la política laboral y la valoración del mercado laboral sobre las características productivas de los individuos, que presenta fallas de mercado que van en detrimento de las minorías poblacionales (en este caso las mujeres) y especialmente del subgrupo de las mejor educadas.

\section{CONCLUSIONES}

El análisis del mercado laboral en Santander efectuado en este documento, presentó los principales indicadores laborales, la descripción estadística de las variables en estudio y una pequeña aproximación a la segregación ocupacional (asignación de hombres y mujeres a determinadas ocupaciones en relación con su rol de género) y diferencias compensatorias (ya que los hombres ocupan cargos que exigen mayores niveles de esfuerzo físico y riesgo). Los resultados fueron similares a Urdinola y Wodon (2003), puesto que en ocupaciones como empleado doméstico (mujeres) y jornalero (hombres), la masificación de la oferta laboral y el bajo nivel educativo hicieron que la población fuese retribuida con salarios inferiores. 
En tal sentido, en este artículo se analizaron los determinantes de los ingresos salariales por género en el departamento de Santander, bajo la teoría del capital humano. Mediante el modelo lineal propuesto en Mincer (1974), se buscó evaluar el efecto que tienen sobre el ingreso laboral por hora las características personales y de capital humano y las características laborales. Las estimaciones exhibieron coeficientes de signos cercanos a los propuestos por la teoría del capital humano; así, la educación tuvo signo positivo en relación con el ingreso, en tanto que la edad y la experiencia tuvieron efectos no lineales frente al ingreso. Ahora bien, la informalidad, en los dos grupos, mostró incidir de forma negativa en el ingreso. Para estas regresiones, la brecha salarial entre hombres y mujeres se ubicó entre un $21 \%$ y 24 $\%$, donde los retornos por educación pasan por un proceso de desfavorecimiento a las mujeres, mientras que los retornos a la edad y experiencia favorecen a los hombres en mayor medida.

Es fundamental señalar que para el total de Santander y para la submuestra de hombres, se observó un sesgo de selección que fue corregido, mientras que en la submuestra de mujeres muy posiblemente los factores de condicionan la participación de la mujer en el mercado laboral no generaron diferencias entre el salario esperado por las desocupadas y el salario percibido por las ocupadas. A partir del análisis de estas variables se encontraron resultados similares a Abadía (2005) y Fernández (2006), puesto que indicadores de compromiso como la tenencia de menores en el hogar y estar casado o conviviendo en pareja representan una penalidad para la participación de la mujer en el mercado laboral, contrario a lo ocurrido para los hombres. Por otra parte, la probabilidad de entrar en el mercado de trabajo se acentúa para mujeres jefes del hogar.

La descomposición Blinder-Oaxaca mostró que la discriminación es el componente que explica en mayor medida la existencia de brechas salariales. Para el caso de Santander, se encontró que las mujeres en promedio devengan un salario entre $25 \%$ y 30 $\%$ menor al de los hombres, por razón de factores no observables asociados a discriminación por género. Entretanto, las diferencias por factores de capital humano evidencian que si las mujeres fueran retribuidas bajo los retornos de capital humano que perciben los hombres, ellas ganarían salarios en promedio mayores a los que reciben. Sin embargo, este componente tan solo alcanza un máximo de 4,38\% en 2012.

Como dato particular, las estimaciones mincerianas determinaron que la valoración de los años de educación incide en el detrimento de las mujeres entre 2012 a 2014 y, dado que el análisis presentado en esta investigación se realizó bajo técnicas estadísticas que toman en cuenta valores promedio de las características de la población, es 
aconsejable efectuar posteriores investigaciones que implementen una metodología alternativa que mida los efectos de las variables explicativas sobre los diferentes intervalos de la distribución salarial. De esta forma se posibilita el análisis de las diferencias que se pueden presentar en los efectos de algunas variables, ya no sobre la media del salario esperado, sino sobre distintos puntos de la distribución condicional de salarios, sean cuantiles o percentiles, de manera tal que en el caso de la educación pueda establecerse si en Santander se encuentran los fenómenos conocidos como Sticky Floor o Glass Ceilling. De igual forma, se recomienda realizar estudios que acudan a fuentes de información que permitan controlar por la posible endogeneidad de la educación, puesto que las estimaciones aquí presentadas pueden estar subvalorando o sobrevalorando las diferencias salariales por género asociadas a discriminación.

Ahora bien, dadas las acciones en materia de política pública que se han propuesto emprender, y en relación con los problemas presentados en este documento, se recomienda que dichas acciones, para la mitigación de los procesos de remuneración inequitativa, permitan determinar su impacto para hombres y mujeres por separado. De esta forma, se lograrán establecer los cambios y procesos requeridos para promover la igualdad de género. Por otra parte, se recomienda que las acciones de política coadyuven a las mujeres a sopesar el peso de sus factores familiares, con el fin de que estos no ejerzan una presión en la participación en el mercado laboral, aceptando cualquier ingreso que el mercado esté dispuesto a ofrecerles.

Además, se recomienda la revisión exhaustiva de los principios que constituyen la política pública de género en la región, pues es pertinente que la política pública se encuentre enmarcada bajo un diagnóstico adecuado, donde se tome en cuenta la relación entre las implicaciones de relaciones de género y los análisis sociales y económicos. Así, se determinarán las decisiones propicias para corregir los problemas de inequidad entre géneros -como las brechas salariales-, sin que estas decisiones o puestas en marcha se encuentren sesgadas por diagnósticos erróneos.

Finalmente, se invita a los hacedores de esta modalidad de política que tomen en cuenta tanto la oferta como la demanda de trabajo, en procura de la equidad de géneros. En la política pública de mujer y equidad de géneros, las acciones por seguir solo contemplan el componente de oferta de mano de obra, dejando de lado el problema en la demanda de trabajo. Es decir, la política no es explícita en la designación de responsabilidades para las empresas empleadoras, siendo estas las causantes de ofrecer a la población en edad de trabajar un trato diferencial, lo que genera tales diferencias de salarios 
por género. Es importante que la política diseñe incentivos en pro de la mitigación de comportamientos discriminatorios que no vayan de acuerdo con el desarrollo íntegro de toda la población santandereana.

\section{REFERENCIAS}

Abadía, L. K. (2005). Discriminación salarial por sexo en Colombia: un análisis desde la discriminación estadística. Documentos de Economía Pontificia Universidad Javeriana, (17).

Actis Di Pasquale, E. \& Atucha, A. J. (2003). Brechas salariales: discriminación o diferencias de productividad. Momento Económico, (126), 23-33.

Alcañiz, M. (2012). Relaciones entre la producción económica y la reproducción social en tiempos de crisis: identidades y roles de género en transformación. En El género de la economía o la economía de género. Actas del VIII Congreso Estatal Isonomía sobre igualdad entre mujeres y hombres (pp. 58-68). Universitat Jaume, Fundación Isonomía.

Amarante, V. \& Espino, A. (2004). La segregación ocupacional de género y las diferencias en las remuneraciones de los asalariados privados. Uruguay, 1990-2000. Revista Desarrollo Económico, 44 (173).

Arrow, K. J. (1972). Some mathematical models of race in the labor market. In A.H. Pascal (ed.), Racial Discrimination in Economic Life. Lexington: Lexington Books.

Arrow, K. (1973, August). Higher education as a filter. Journal of Public Economics, 2(3), 193-216.

Atal, J., Nopo, H. \& Winder, N. (2009, October). New century, old disparities: gender and ethnic wage gaps in Latin America. IDB Working Papers.

Badel, A. \& Peña, X. (2009). Decomposing the gender wage gap with sample selection adjustment: evidence from Colombia. Bogotá, Colombia: Universidad de los Andes.

Baquero, J. (2001). Estimación de la discriminación salarial por género para los trabajadores asalariados urbanos de Colombia (1984-1999). Borradores de Investigación Universidad del Rosario, (2593).

Becker, G. S. (1962). Investment in human capital: A theoretical analysis. The Journal of Political Economy, 70(5), 9-49.

Becker, G. S. (1964). Human capital: a theoretical and empirical analysis, with special reference to education. New York: Columbia.

Becker, G. S. (1985). Human capital, effort, and the sexual division of labor. Journal of Labor Economics, 3(1), 33-58. 
Benería, L. (2004). La mujer y el género en la economía: un panorama general. En Gender, Development and Globalization. Barcelona: Icaria.

Bernat, L. (2005). Análisis de género de las diferencias salariales en las siete principales áreas metropolitanas colombianas: ¿evidencia de discriminación? Documento PNUD. Recuperado de http://www.pnud.org.co/img_upload/ 9056f18133669868e1cc381983d50faa/65_78.pdf

Blaconá, M. T., García, M., Borgognone, M. G., Bussi, J., Ventroni, N. \& Pellegrini, J. L. (2001). Consideraciones metodológicas sobre la estimación econométrica de las ecuaciones de ingresos de los integrantes de la pareja conyugal. En Reunión Anual de la Asociación Argentina de Economía Política. Vol. 31.

Blau, F. D. \& Kahn, L. M. (2000). Gender differences in pay. Cambridge, MA: National Bureau of Economic Research.

Blinder, A. (1973). Wage Discrimination: Reduced form and Structural Estimates. The Journal of Human Resources, 8(4), 436-455.

Brizuela, S. \& Tumini, L. (2008). Inequidades de género en el mercado de trabajo de la Argentina: las brechas salariales. Revista de Trabajo, 4(6).

Cain, G. (1986). The economic analysis of labor market discrimination: a survey. Madison, USA: University of Wisconsin-Madison, Institute for Research on Poverty.

Carrasco, A. S. E. (2001). Los retornos de la inversión en capital humano en Bolivia. Revista Análisis Económico UDAPE, 19, 1-26.

Casas, A., Sepúlveda, C. \& Gallego, J. (2003). Retornos de la educación y sesgo de habilidad: teoría y aplicaciones en Colombia. Lecturas de Economía, (58), 69-96.

Contreras, D. \& Gallegos, S. (2011). Desigualdad salarial en América Latina: una década de cambios. Revista de la CEPAL, (103).

Correa, J. B., Viáfara, C. A. \& Zuluaga, V. H. (2011). Desigualdad étnico-racial en la distribución del ingreso en Colombia: un análisis a partir de regresión cuantílica. Sociedad y Economía, (19), 153-178.

DANE. (2013, 28 de feb.). Principales indicadores del mercado laboral, departamentos, 2012. Boletín de prensa. Bogotá: DANE.

De la Rica, S. \& Ugidos, A. (1995). ¿Son las diferencias en capital humano determinantes de las diferencias salariales observadas entre hombres y mujeres? Investigaciones Económicas, 19(3), 395-414.

Deininger, K., Jin, S. \& Nagarajan, H. (2013). Wage Discrimination in India's Informal Labor Markets: Exploring the Impact of Caste and Gender. Review of Development Economics, 17(1), 130-147.

Drolet, M. (2001). The persistent gap: New evidence on the Canadian gender wage gap Analytical Studies Branch, Research Paper Series, (157).

El-Hamidi, F. \& Said, M. (2014). Gender-based wage and occupational inequality in the new millenium in Egypt. The Journal of Developing Areas, 48(1), 21-41. 
Esquivel, V. (2007). Género y diferenciales de salarios en la Argentina. M. Novick \& H. Palomino, (coord.), Estructura productiva y empleo: un enfoque transversal. Buenos Aires, Argentina: Ministerio de Trabajo, Empleo y Seguridad Social.

Fernández, M. (2006). Determinantes del diferencial salarial por género en Colombia 1997-2003. Revista Desarrollo y Sociedad, 58, 165-208.

Flórez, C. (2004). La transformación de los hogares: una visión de largo plazo. Revista Coyuntura Social, (30), 23-49.

García, A. (1989). Patrones de desigualdad social en la sociedad moderna: Una revisión de la literatura sobre discriminación ocupacional y salarial por género. Revista Desarrollo Económico, 49(114).

Gobernación de Santander. (2010). Política pública de mujer y equidad de géneros en Santander. Plan decenal de igualdad de oportunidades sobre la mujer 2010-2019 (PPMIGS- PIO).

Gómez, A. \& Ramírez, Z. (2015). Disparidades salariales y la tasa interna de retorno a la educación privada en los docentes de la Universidad del Cauca. Revista Civilizar Ciencias Sociales y Humanas, 15(28), 165-180

Griliches, Z. (1977). Estimating the returns to schooling: some econometric problems. Econometrica, 45(1), 1-22.

Guataquí, J. C., García, A. F. \& Rodríguez, M. (2009). Estimaciones de los determinantes de los ingresos laborales en Colombia con consideraciones diferenciales para asalariados y cuenta propia. Documentos de Trabajo, 70, 1-22.

Guzmán, V. \& Torado, R. (2001). Apuntes sobre género en la economía global. Ediciones de las mujeres, (32), 15-23.

Hausman, J. A. \& W. E. Taylor, (1981, Nov.). Panel data and unobservable individual effects. Econometrica, 49(6), 1377-1398.

Heckman, J. J. (1979). Sample selection bias as a specification error. Econometrica: Journal of the Econometric Society, 47(1), 153-161.

Hernández, P. J. M. (1995). Análisis empírico de la discriminación salarial de la mujer en España. Investigaciones Económicas, 19(2), 195-215.

Korkeamäki, O. \& Kyyrä, T. (2006). A gender wage gap decomposition for matched employer-employee data. Labour Economics, 13(5), 611-638.

Kunze, A. (2005). The evolution of the gender wage gap. Labour Economics, 12(1), 73-97.

Machin, S. \& Puhani, P. A. (2003). Subject of degree and the gender wage differential: evidence from the UK and Germany. Economics Letters, 79(3), 393-400.

Mincer, J. (1958). Investment in Human Capital and Personal Income Distribution. The Journal of Political Economy, 66(4), 281-302.

Mincer, J. \& Polachek, S. (1974). Family investments in human capital: Earnings of women. In Marriage, family, human capital, and fertility. Journal of Political Economy 82(2), 76-110. 
Ortiz, C. H., Uribe, J. I. \& García, G. A. (2007). Informalidad y subempleo: un modelo probit bivariado aplicado al Valle del Cauca. Sociedad y Economía, (13), 104-131.

Peña, X., Cárdenas, J., Ñopo, H., Castañeda, J., Muñoz, J. \& Uribe, C. (2013). Mujer y movilidad social. Documento CEDE Universidad de los Andes, 5.

Phelps, E. (1972). The Statistical Theory of Racism and Sexism. American Economic Review 62(4), 659-661.

Piore, M. J. (1970). The Dual Labor Market: Theory and Implications. S. H. Beer \& R.E. Barringer (ed.). The State and the Poor. Cambridge, MA: Winthrop.

Shultz, T. (1961). Investment in Human Capital. The American Economic Review, 51(1), $1-17$.

Sivard, R. (1985). Women a world survey. Washington, D.C.: World Priorities.

Spence, M.A. (1973, August). Job Market Signalling. Quarterly Journal of Economics, $87(3), 355-374$.

Tenjo, J. (1993). Cambios en diferenciales salariales entre hombres y mujeres: 19761989. En Planeación y Desarrollo (pp. 117-132) Bogotá: DNP.

Tenjo, J., Ribero, R. \& Bernat, L. (2005). Evolución de las diferencias salariales por sexo en seis países de América Latina: un intento de interpretación. Bogotá: CEDE, Centro de Estudios sobre Desarrollo Económico, Facultad de Economía, Universidad de los Andes.

Tenjo, J. \& Herrera, P. (2009). Dos ensayos sobre discriminación: discriminación salarial y discriminación en acceso al empleo por origen étnico y por género. Bogotá: Pontificia Universidad Javeriana, Documentos de Economía.

Urdinola, D. F. A. \& Wodon, Q. (2003). Relative labor supply and the gender wage Gap: Evidence for Colombia and the United States (003452). Bogotá: Departamento Nacional de Planeación.

Uribe, J. \& Ortiz, C. (2006). Informalidad laboral en Colombia 1988-2000: evolución, teorías y modelos. Cali, Colombia: Programa Editorial Universidad del Valle.

Varela L. R., Ocegueda H., J. M., Castillo P., R. \& Huber B., G. (2010). Determinantes de los ingresos salariales en México: una perspectiva de capital humano. Región y Sociedad, 22(49), 117-142.

Witkowska, D. (2013). Gender Disparities in the Labor Market in the EU. International Advances in Economic Research, 19(4), 331-354. 
Apuntes CENES Volumen 35, Número 61, ISSN 0120-3053

enero - junio 2016, Págs. 267-302

\section{ANEXOS}

Anexo 1. Estadísticas descriptivas del ingreso. Población total y por sexo, 2012-2014

\begin{tabular}{|c|c|c|c|c|c|c|c|}
\hline 虽 & Población & Variable & $\begin{array}{c}\text { Observa- } \\
\text { ciones }\end{array}$ & Media & $\begin{array}{l}\text { Desviación } \\
\text { estándar }\end{array}$ & Mínimo & Máximo \\
\hline \multirow{6}{*}{ 뭉 } & \multirow{2}{*}{ TOTAL } & Ingreso mensual & \multirow{2}{*}{14373} & 975.794 & 1.251 .624 & 0 & 60.000 .000 \\
\hline & & Ingreso por hora & & 5.490 & 7.831 & 0 & 425.000 \\
\hline & \multirow{2}{*}{ Hombres } & Ingreso mensual & \multirow{2}{*}{7836} & 1.113 .800 & 1.435 .337 & 0 & 60.000 .000 \\
\hline & & Ingreso por hora & & 5.788 & 8.654 & 0 & 425.000 \\
\hline & \multirow{2}{*}{ Mujeres } & Ingreso mensual & \multirow{2}{*}{6537} & 810.363 & 961.695 & 0 & 20.000 .000 \\
\hline & & Ingreso por hora & & 5.133 & 6.695 & 0 & 166.667 \\
\hline \multirow{6}{*}{$\stackrel{m}{\stackrel{m}{n}}$} & \multirow{2}{*}{ TOTAL } & Ingreso mensual & \multirow{2}{*}{14344} & 947.873 & 1.058 .031 & 0 & 34.300 .000 \\
\hline & & Ingreso por hora & & 5.293 & 7.331 & 0 & 367.863 \\
\hline & \multirow{2}{*}{ Hombres } & Ingreso mensual & \multirow{2}{*}{7732} & 1.075 .960 & 1.190 .115 & 0 & 34.300 .000 \\
\hline & & Ingreso por hora & & 5.561 & 6.778 & 0 & 183.932 \\
\hline & \multirow{2}{*}{ Mujeres } & Ingreso mensual & \multirow{2}{*}{6612} & 798.090 & 854.824 & 0 & 17.200 .000 \\
\hline & & Ingreso por hora & & 4.981 & 7.918 & 0 & 367.863 \\
\hline \multirow{6}{*}{ 䓂 } & \multirow{2}{*}{ TOTAL } & Ingreso mensual & \multirow{2}{*}{14187} & 957681,4 & 1020906 & 0 & 30.300 .000 \\
\hline & & Ingreso por hora & & 5.308 & 6.276 & 0 & 189.269 \\
\hline & \multirow{2}{*}{ Hombres } & Ingreso mensual & \multirow{2}{*}{7585} & 1.082 .738 & 1.135 .586 & 0 & 30.300 .000 \\
\hline & & Ingreso por hora & & 5.578 & 6.572 & 0 & 189.269 \\
\hline & \multirow{2}{*}{ Mujeres } & Ingreso mensual & \multirow{2}{*}{6602} & 814.004 & 848.326 & 0 & 14.200 .000 \\
\hline & & Ingreso por hora & & 4.998 & 5.903 & 0 & 138.797 \\
\hline
\end{tabular}


Diferencias salariales por género en el departamento de Santander - Colombia Alexandra Cortés Aguilar • María Alejandra Flórez Vera

Anexo 2. Medias de variables explicativas por sexo, 2012-2014

\begin{tabular}{|c|c|c|c|c|c|c|}
\hline \multirow{2}{*}{ Variable } & \multicolumn{2}{|c|}{2012} & \multicolumn{2}{|c|}{2013} & \multicolumn{2}{|c|}{2014} \\
\hline & Hombre & Mujer & Hombre & Mujer & Hombre & Mujer \\
\hline \multicolumn{7}{|c|}{ Capital humano } \\
\hline Edad & 36,840 & 37,008 & 37,157 & 37,190 & 37,014 & 37,121 \\
\hline Asistencia escolar & 0,081 & 0,112 & 0,092 & 0,105 & 0,086 & 0,110 \\
\hline Antigüedad en la empresa & 6,170 & 4,951 & 5,997 & 4,865 & 5,900 & 4,763 \\
\hline \multicolumn{7}{|c|}{ Características del empleo } \\
\hline Condición de informal & 0,590 & 0,623 & 0,574 & 0,617 & 0,557 & 0,596 \\
\hline Trabajador de tiempo Completo & 0,905 & 0,713 & 0,903 & 0,722 & 0,912 & 0,737 \\
\hline \multicolumn{7}{|c|}{ Tipo de ocupación } \\
\hline Empleado de empresa & 0,407 & 0,371 & 0,441 & 0,396 & 0,455 & 0,408 \\
\hline Empleado público & 0,034 & 0,042 & 0,031 & 0,038 & 0,033 & 0,039 \\
\hline Empleado doméstico & 0,001 & 0,065 & 0,002 & 0,064 & 0,002 & 0,062 \\
\hline Cuenta propia & 0,429 & 0,463 & 0,423 & 0,451 & 0,404 & 0,445 \\
\hline Empleador & 0,101 & 0,050 & 0,080 & 0,043 & 0,082 & 0,039 \\
\hline Sin pago & 0,001 & 0,002 & 0,001 & 0,002 & 0,001 & 0,002 \\
\hline Jornalero & 0,023 & 0,003 & 0,021 & 0,003 & 0,020 & 0,002 \\
\hline Otra ocupación & 0,003 & 0,005 & 0,001 & 0,003 & 0,003 & 0,003 \\
\hline \multicolumn{7}{|c|}{ Tamaño de la empresa } \\
\hline Microempresa & 0,599 & 0,621 & 0,594 & 0,617 & 0,578 & 0,608 \\
\hline Empresa pequeña & 0,098 & 0,090 & 0,091 & 0,087 & 0,098 & 0,097 \\
\hline Empresa mediana & 0,076 & 0,071 & 0,084 & 0,079 & 0,088 & 0,080 \\
\hline Empresa grande & 0,227 & 0,219 & 0,231 & 0,217 & 0,236 & 0,214 \\
\hline \multicolumn{7}{|c|}{ Características familiares } \\
\hline Con pareja & 0,626 & 0,526 & 0,629 & 0,526 & 0,614 & 0,516 \\
\hline Jefe de hogar & 0,619 & 0,273 & 0,611 & 0,289 & 0,597 & 0,280 \\
\hline $\begin{array}{l}\text { Infantes menores a } 6 \text { años en el } \\
\text { hogar }\end{array}$ & 0,348 & 0,358 & 0,336 & 0,350 & 0,329 & 0,350 \\
\hline \multicolumn{7}{|c|}{ Último nivel de educación alcanzado } \\
\hline Primaria o menos & 0,282 & 0,207 & 0,283 & 0,198 & 0,243 & 0,214 \\
\hline Secundaria & 0,134 & 0,124 & 0,134 & 0,127 & 0,123 & 0,121 \\
\hline Media & 0,291 & 0,274 & 0,286 & 0,274 & 0,301 & 0,277 \\
\hline Superior & 0,272 & 0,383 & 0,281 & 0,391 & 0,311 & 0,370 \\
\hline
\end{tabular}




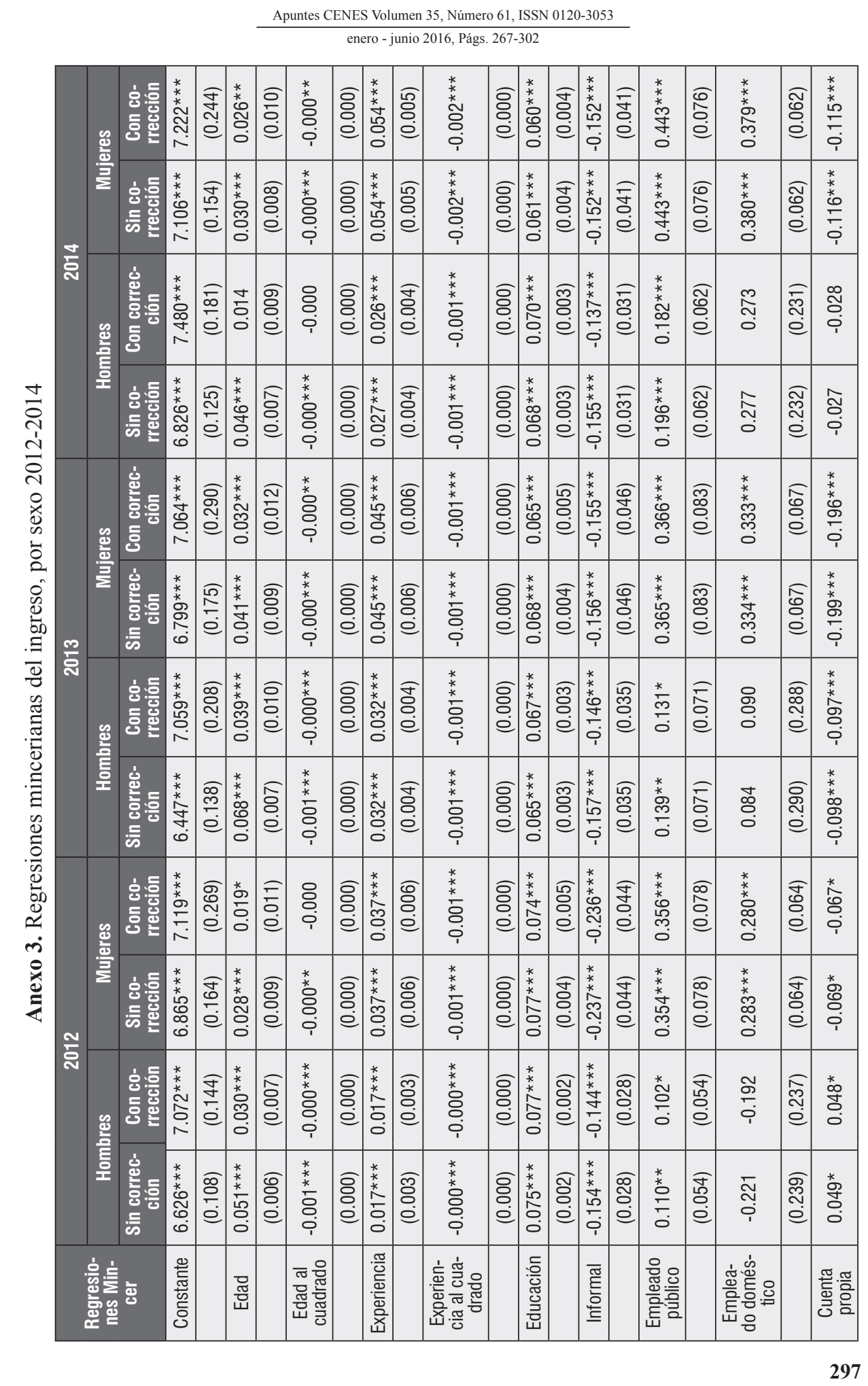




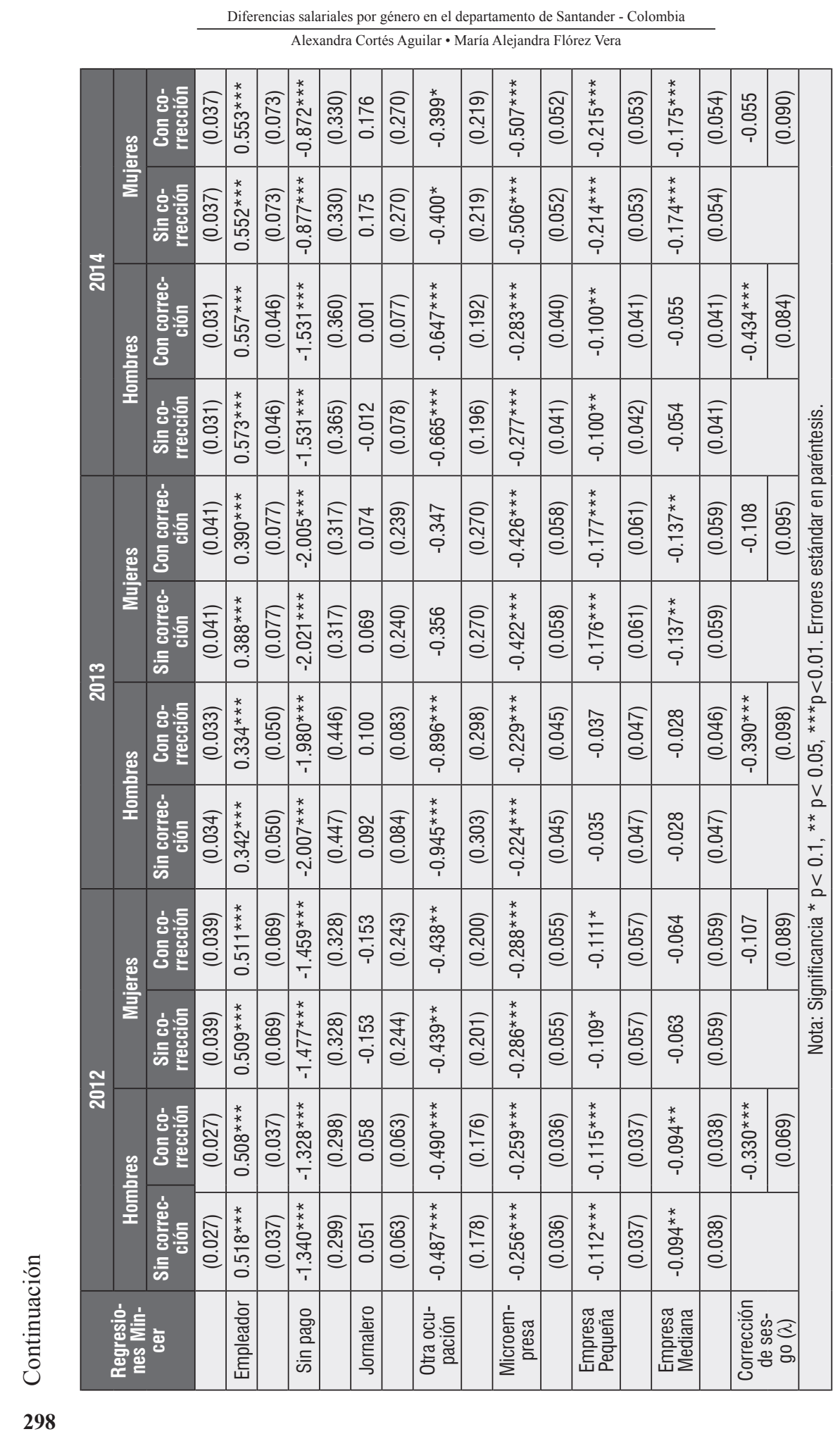


Anexo 4. Factores que inciden en la participacion laboral de hombres y mujeres, año 2012

\begin{tabular}{|c|c|c|c|c|c|c|}
\hline \multirow{3}{*}{$\begin{array}{l}\text { Probabilidad de estar } \\
\text { ocupado } \\
\text { Variable }\end{array}$} & \multicolumn{3}{|c|}{ HOMBRES } & \multicolumn{3}{|c|}{ MUJERES } \\
\hline & \multicolumn{3}{|c|}{0,9001} & \multicolumn{3}{|c|}{0,6890} \\
\hline & \multicolumn{2}{|c|}{ Coeficiente } & Efecto marginal & \multicolumn{2}{|c|}{ Coeficiente } & Efecto marginal \\
\hline \multirow[t]{2}{*}{ Edad } & 0,1263 & $* * *$ & 0,0221 & 0,1590 & $\star * *$ & 0,0562 \\
\hline & 0,0105 & & 0,0018 & 0,0079 & & 0,0028 \\
\hline \multirow[t]{2}{*}{ Edad al cuadrado } & $-0,0017$ & $* * *$ & $-0,0003$ & $-0,0020$ & $* * *$ & $-0,0007$ \\
\hline & 0,0001 & & 0,0000 & 0,0001 & & 0,0000 \\
\hline \multirow[t]{2}{*}{ Años de educación } & $-0,0002$ & & 0,0000 & 0,0347 & $\star * *$ & 0,0123 \\
\hline & 0,0044 & & 0,0008 & 0,0033 & & 0,0012 \\
\hline \multirow[t]{2}{*}{ Casado o en unión } & 0,2239 & $* * *$ & 0,0402 & $-0,2475$ & $\star * *$ & $-0,0865$ \\
\hline & 0,0504 & & 0,0093 & 0,0307 & & 0,0106 \\
\hline \multirow[t]{2}{*}{ Jefe del hogar } & 0,4519 & $* \star *$ & 0,0828 & 0,2508 & $* * *$ & 0,0852 \\
\hline & 0,0488 & & 0,0092 & 0,0363 & & 0,0118 \\
\hline \multirow[t]{2}{*}{ Asistencia escolar } & $-0,7825$ & $* \star *$ & $-0,1915$ & $-0,3736$ & $\star * *$ & $-0,1392$ \\
\hline & 0,0517 & & 0,0162 & 0,0434 & & 0,0168 \\
\hline \multirow[t]{2}{*}{ Niños en el hogar } & 0,1437 & $* \star *$ & 0,0244 & $-0,1167$ & $* * *$ & $-0,0415$ \\
\hline & 0,0450 & & 0,0074 & 0,0286 & & 0,0102 \\
\hline
\end{tabular}

Nota: significancia $* \mathrm{p}<0.1,{ }^{* *} \mathrm{p}<0.05,{ }^{* * *} \mathrm{p}<0.01$. Errores estándar en paréntesis. 
Anexo 5. Factores que inciden en la participacion laboral de hombres y mujeres, año 2013

\begin{tabular}{|c|c|c|c|c|c|c|}
\hline \multirow{3}{*}{$\begin{array}{l}\text { Probabilidad de estar } \\
\text { ocupado } \\
\text { Variable }\end{array}$} & \multicolumn{3}{|c|}{ HOMBRES } & \multicolumn{3}{|c|}{ MUJERES } \\
\hline & \multicolumn{3}{|c|}{0,8943} & \multicolumn{3}{|c|}{0,7049} \\
\hline & \multicolumn{2}{|c|}{ Coeficiente } & $\begin{array}{l}\text { Efecto mar- } \\
\text { ginal }\end{array}$ & \multicolumn{2}{|c|}{ Coeficiente } & Efecto marginal \\
\hline \multirow[t]{2}{*}{ Edad } & 0,1491 & $\star \star \star$ & 0,0272 & 0,1639 & $\star * *$ & 0,0566 \\
\hline & 0,0103 & & 0,0019 & 0,0081 & & 0,0028 \\
\hline \multirow[t]{2}{*}{ Edad al cuadrado } & $-0,0020$ & $* * *$ & $-0,0004$ & $-0,0021$ & $\star * *$ & $-0,0007$ \\
\hline & 0,0001 & & 0,0000 & 0,0001 & & 0,0000 \\
\hline \multirow[t]{2}{*}{ Años de educación } & $-0,0010$ & & $-0,0002$ & 0,0413 & $\star * \star$ & 0,0142 \\
\hline & 0,0045 & & 0,0008 & 0,0033 & & 0,0012 \\
\hline \multirow[t]{2}{*}{ Casado o en unión } & 0,3178 & $\star * *$ & 0,0599 & $-0,2083$ & $* * *$ & $-0,0713$ \\
\hline & 0,0486 & & 0,0094 & 0,0311 & & 0,0105 \\
\hline \multirow[t]{2}{*}{ Jefe del hogar } & 0,3440 & $\star * *$ & 0,0646 & 0,2901 & $\star \star * \star$ & 0,0955 \\
\hline & 0,0468 & & 0,0090 & 0,0363 & & 0,0113 \\
\hline \multirow[t]{2}{*}{ Asistencia escolar } & $-0,5934$ & $* * *$ & $-0,1392$ & $-0,3786$ & $* * *$ & $-0,1388$ \\
\hline & 0,0511 & & 0,0147 & 0,0439 & & 0,0168 \\
\hline \multirow[t]{2}{*}{ Niños en el hogar } & 0,1079 & $\star \star$ & 0,0192 & $-0,1003$ & $\star * *$ & $-0,0348$ \\
\hline & 0,0444 & & 0,0077 & 0,0293 & & 0,0102 \\
\hline
\end{tabular}

Nota: significancia $* \mathrm{p}<0.1,{ }^{* *} \mathrm{p}<0.05,{ }^{* * *} \mathrm{p}<0.01$. Errores estándar en paréntesis. 
Anexo 6. Factores que inciden en la participacion laboral de hombres y mujeres, año 2014

\begin{tabular}{|c|c|c|c|c|c|c|}
\hline \multirow{3}{*}{$\begin{array}{l}\text { Probabilidad de estar } \\
\text { ocupado } \\
\text { Variable }\end{array}$} & \multicolumn{3}{|c|}{ HOMBRES } & \multicolumn{3}{|c|}{ MUJERES } \\
\hline & \multicolumn{3}{|c|}{0,9054} & \multicolumn{3}{|c|}{0,7196} \\
\hline & \multicolumn{2}{|c|}{ Coeficiente } & \multirow{2}{*}{$\begin{array}{c}\text { Efecto marginal } \\
0,0265\end{array}$} & \multicolumn{2}{|c|}{ Coeficiente } & \multirow{2}{*}{$\begin{array}{c}\begin{array}{c}\text { Efecto mar- } \\
\text { ginal }\end{array} \\
0,0479\end{array}$} \\
\hline Edad & 0,1570 & $* * *$ & & 0,1422 & $* * *$ & \\
\hline & 0,0108 & & 0,0018 & 0,0081 & & 0,0027 \\
\hline \multirow[t]{2}{*}{ Edad al cuadrado } & $-0,0021$ & $* * *$ & $-0,0004$ & $-0,0019$ & $\star * *$ & $-0,0006$ \\
\hline & 0,0001 & & 0,0000 & 0,0001 & & 0,0000 \\
\hline \multirow[t]{2}{*}{ Años de educación } & 0,0054 & & 0,0009 & 0,0385 & $* * *$ & 0,0130 \\
\hline & 0,0046 & & 0,0008 & 0,0034 & & 0,0011 \\
\hline \multirow[t]{2}{*}{ Casado o en unión } & 0,2669 & $\star \star \star *$ & 0,0461 & $-0,2440$ & $\star \star * *$ & $-0,0814$ \\
\hline & 0,0489 & & 0,0086 & 0,0314 & & 0,0104 \\
\hline \multirow{2}{*}{ Jefe del hogar } & 0,4428 & 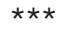 & 0,0771 & 0,2072 & $\star \star \star *$ & 0,0674 \\
\hline & 0,0483 & & 0,0085 & 0,0365 & & 0,0114 \\
\hline \multirow[t]{2}{*}{ Asistencia escolar } & $-0,6956$ & 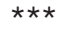 & $-0,1599$ & $-0,4833$ & $\star \star \star *$ & $-0,1761$ \\
\hline & 0,0525 & & 0,0153 & 0,0437 & & 0,0168 \\
\hline \multirow[t]{2}{*}{ Niños en el hogar } & 0,0599 & & 0,0099 & $-0,0996$ & $\star \star \star *$ & $-0,0338$ \\
\hline & 0,0452 & & 0,0074 & 0,0297 & & 0,0102 \\
\hline
\end{tabular}

Nota: significancia $* \mathrm{p}<0.1,{ }^{* *} \mathrm{p}<0.05,{ }^{* * *} \mathrm{p}<0.01$. Errores estándar en paréntesis. 
